\title{
Professional learning and development framework for postdoctoral scholars
}

\author{
Lorelli Nowell and Swati Dhingra \\ Faculty of Nursing, University of Calgary, Calgary, Canada \\ Natasha Kenny \\ Taylor Institute for Teaching and Learning, University of Calgary, Calgary, Canada \\ Michele Jacobsen \\ Werklund School of Education, University of Calgary, Calgary, Canada, and \\ Penny Pexman \\ Department of Psychology, University of Calgary, Calgary, Canada
}

\begin{abstract}
Purpose - Many postdoctoral scholars are seeking professional learning and development (PLD) opportunities to prepare for diverse careers, roles and responsibilities. This paper aims to develop an evidence-informed framework for PLD of postdoctoral scholars that speaks to these changing career paths.

Design/methodology/approach - This paper used an integrated knowledge translation approach to synthesize and extend previous work on postdoctoral scholars' PLD. The authors engaged in consultations with key stakeholders and synthesized findings from literature reviews, surveys and semi-structured interviews to create a framework for PLD.

Findings - The PLD framework consists of four major domains, namely, professional socialization; professional skills; academic development; and personal effectiveness. The 4 major domains are subdivided into 16 subdomains that represent the various skills and competencies that postdoctoral scholars can build throughout their postdoctoral fellowships.

Originality/value - The framework can be used to support postdoctoral scholars, postdoctoral supervisors and higher education institutions in developing high quality, evidence-informed PLD plans to meet the diverse career needs of postdoctoral scholars.
\end{abstract}

Keywords Postdoctoral scholars, Professional learning, Professional development,

Mixed-methods research, Higher education

Paper type Research paper

(C) Lorelli Nowell, Swati Dhingra, Natasha Kenny, Michele Jacobsen and Penny Pexman. Published by Emerald Publishing Limited. This article is published under the Creative Commons Attribution (CC BY 4.0) licence. Anyone may reproduce, distribute, translate and create derivative works of this article (for both commercial and non-commercial purposes), subject to full attribution to the original publication and authors. The full terms of this licence maybe seen at http://creativecommons.org/licences/by/4.0/legalcode

The research team gratefully acknowledges the contributions from all of the postdoctoral scholar participants from the University of Calgary who shared their experiences and insights on professional learning and development. The authors appreciate the contribution and support of postdoctoral supervisors and academic leaders who provided valuable feedback on our framework.

Funding: Lorelli Nowell was supported in this work by an Eyes High Postdoctoral Fellowship. This research was funded in part by a Scholarship of Teaching and Learning (SoTL) Grant from the University of Calgary.

Postdoctoral scholars

Received 2 October 2020 Revised 3 February 2021 20 April 2021 Accepted 10 May 2021

Acced 10 May 2021

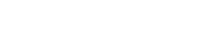


SGPE

12,3

\section{Introduction}

As qualified early career researchers, postdoctoral scholars (postdocs) are an essential component of a country's research community and play a key role in driving discovery and expanding knowledge (Jadavji et al., 2016; Mitchell et al., 2013). Postdocs study relevant problems, address important societal issues and inform future policy (Jadavji et al., 2016; Mitchell et al., 2013). Postdocs hold doctoral degrees and are engaged in mentored research and/or scholarly training for the purpose of developing their intellectual independence, academic excellence and entrepreneurial skills (Nerad and Cerny, 1999; Silva et al., 2016). These skills are essential to thrive in an evolving society and labor market. However, over the course of their fellowships, postdocs often express confusion and uncertainty about their future careers (Åkerlind, 2005; Powell, 2015; Sauermann and Roach, 2016).

Fewer than $20 \%$ of postdocs enter permanent academic positions (Edge and Munro, 2015; Fuhrmann et al., 2011). However, the training postdocs seek and receive is designed to prepare them for academic careers and rarely includes the professional skills needed to succeed in non-academic settings (Jadavji et al., 2016; Mitchell et al., 2013). Postdocs' perceptions of the usefulness of professional learning and development (PLD) opportunities vary widely, and the types of opportunities offered are frequently not aligned with the reality of the diversity and range of possible future careers (Nowell et al., 2019). Job markets and workforce needs have clearly changed for postdoctoral scholars, extending much beyond traditional academic roles in universities, to include diverse careers in the government, not-for-profit and private sectors (Ålund et al., 2020; Council of Canadian Academies, 2021). Despite the integral role postdocs play in research productivity, there has been no detailed study to understand postdocs' PLD, and the effectiveness of strategies implemented to support their growth.

Postdocs' PLD is a multifaceted, heterogeneous phenomenon. Therefore, its implementation, comparison and evaluation are problematic. The sparse and diverse postdoc PLD literature, together with differences in higher education institutions' sizes, mandates and programs complicates the comparison of PLD across institutions. In response to changing workforce needs, many universities do offer some sort of additional career development activities for postdocs; however, these activities often lack systematic planning, implementation and prioritization (Allund et al., 2020). Given the significant resources required to support postdoc PLD, a careful compilation of indicators needs to be developed to measure the achievement of goals and outcomes and to prioritize effective PLD strategies.

There are a number of models and frameworks that have been designed to support the overall development of researchers, often created to be used across a research career trajectory, from graduate school to expert independent researcher and targeted toward a specific university or country context. These frameworks may have many benefits for those on a clear research development pathway, however, many fail to take into consideration the unique and precarious positions that many postdocs find themselves in with limited numbers of academic and research positions available to them post-fellowship. Moreover, it is not always clear if these frameworks were developed in consultation with multistakeholders who may provide valuable information and insight into the broad learning, development and workforce needs.

In the UK, the Vitae Researcher Development Framework was developed to aid in planning, promoting and enhancing professional and career development of researchers in higher education (Bray and Boon, 2011). This framework has been extended to include an employability lens, engineering lens and enterprise lens to highlight the knowledge and skills that are relevant for these various research foci 
(Vitae Careers Research and Advisory Centre, 2021). Similarly, the University of Cambridge (2021) Researcher Development Framework was developed to support researcher development in interdisciplinary contexts. While these frameworks certainly have great value to those looking to pursue research careers, they were created within a specific UK context and were not purposefully designed to meet the unique needs of postdoctoral scholars who may be focused on or forced into careers outside of research.

Across Europe more broadly there is a European Framework for Research Careers (European Commission Directorate General for Research and Innovation, 2011). This framework describes four broad profiles from first stage researcher to leading researcher and was created to apply to all researchers regardless of where they work (companies, Non Government Organizations, research institutions, universities, etc.). Though this framework is certainly relevant and useable by researchers across settings, postdoctoral scholars who choose not to focus on research careers may not see the relevance of this framework for their desired career path.

Universities across Australia, including Adelaide University, the University of Canberra, Edith Cowan University and the University of New South Wales have created researcher skills development frameworks for their specific contexts. Although these frameworks are useful to understand research skills required for academics, they were created to be used within distinct Australian Universities and do not highlight the unique needs of postdoctoral scholars, especially those who may choose to focus on careers outside of academia and/or research altogether.

Linda Evans' (2012, 2014) work focused specifically on leadership development for researchers including behavioral, attitudinal and intellectual development. Although leadership is certainly an important skill, which can contribute to postdoctoral scholars' PLD, Evans' work is focused specifically on supporting the successful development of researchers in higher education and may not meet the needs of researchers who work in other settings or postdoctoral scholars who may seek work outside of academia or other research intensive environments.

In the USA, the National Postdoctoral Association (NPA) was established in 2002 to provide a national voice for postdoctoral scholars and improve the postdoctoral experience by supporting enhanced research training and professional growth (National Postdoctoral Association, 2021). The NPA advocates for postdoctoral scholars to master competencies in discipline-specific conceptual knowledge, research skill development, communication skills, professionalism, leadership and management skills and responsible conduct of research. The NPA offers a number of resources and literature associated with each of the identified areas of skill development. Interestingly, it is unclear if these competencies were created in consultation with postdoctoral scholars or industry stakeholders who may have valuable insights that could be used to strengthen this resource.

\section{Research aims}

The aim of this research was to synthesize and extend our previous research, and that of others, to develop an evidence-informed PLD framework that may be used by:

- Postdocs, to evaluate and plan for PLD opportunities.

- Postdoctoral supervisors, to support the PLD of the postdocs they supervise.

- Postdoctoral administrators, to plan and provide PLD support for postdocs.

- Institutional decision-makers, to inform strategies related to postdoc PLD. 
SGPE

12,3
- Employers, to gain insight into the broad range of skills and expertise that postdocs bring to the workforce.

\section{Design and methods}

We used an integrated knowledge translation approach (Graham et al., 2006) to develop our framework. Our multidisciplinary team, all based at the same institution, included a postdoc, a postdoctoral program director, postdoctoral supervisors and the director of educational development. The team co-developed the research questions and was involved throughout the framework development process. We used results from our previous mixedmethods research including evidence synthesis, document analysis, surveys and semistructured interviews, to inform consultations with key stakeholders and to develop and refine our evidence informed framework.

\section{Evidence synthesis}

Two extensive literature reviews were completed. The first examined and synthesized evidence of postdoc PLD (Nowell et al., 2018). The second synthesized the literature that described current approaches to PLD for postdocs (Nowell et al., 2019). Findings from these reviews informed the development of the survey and semi-structured interviews.

\section{Document analysis}

Strategic documents related to the development, decision-making, operation and evaluation of a large institutional postdoc professional development program at one institution were collected and thematically analyzed. The Postdoctoral Scholar Program originated in 2013, when the institution's research leaders announced a strategic decision to invest in such support. This decision has since resulted in substantially increased numbers of postdocs at the institution. The program strives to provide postdocs with a competitive edge in the global job market through promoting excellence in scholarship, teaching, leadership, mentorship, knowledge translation, collaboration, community engagement and career development. The findings from the document analysis were used to develop the subsequent survey, refine the semi-structured interview guide and document current professional development supports.

\section{Survey}

A survey was developed based on the results of the evidence synthesis and document analysis. The survey was directed at postdocs from the same institution mentioned above. It included demographic items, as well as questions about professional development opportunities, namely, perceptions of, learning gained and utilization of knowledge and skills developed. The results of the survey are published elsewhere (Nowell et al., 2019), and generally emphasized the usefulness and importance of professional development opportunities related to teaching and learning, project management and time management, academic writing, career planning and academic career skills.

\section{Semi-structured interviews}

Postdocs who agreed to be interviewed were purposively sampled based on survey results and selected to capture variations across genders, disciplines and years of postdoc experience. The interview guide consisted of open-ended questions designed to explore each participant's perspective and involvement with PLD opportunities. The results of the 
interviews are published elsewhere (Nowell et al., 2019), and indicated the value, relevance and importance of professional learning to postdocs from a professional, academic and personal context.

\section{Data triangulation}

Moving beyond and building from our previous work, we undertook a process of triangulating findings from the different methods after all of the data sets had been analyzed separately. Triangulation occurred using a mixed-methods meta-matrix (O'Cathain et al., 2010; Wendler, 2001) where we listed the findings from each component of the study on the same page to consider where findings from each method converged, complemented each other or contradicted each other. Using this technique of integration, all data were analyzed in detail together. The use of a meta-matrix facilitated a robust visual anchor to enhance pattern recognition between data types and create a solid documentation trail (Wendler, 2001). The final result of this process was the comprehensive summary and visual framework for postdoctoral PLD described here.

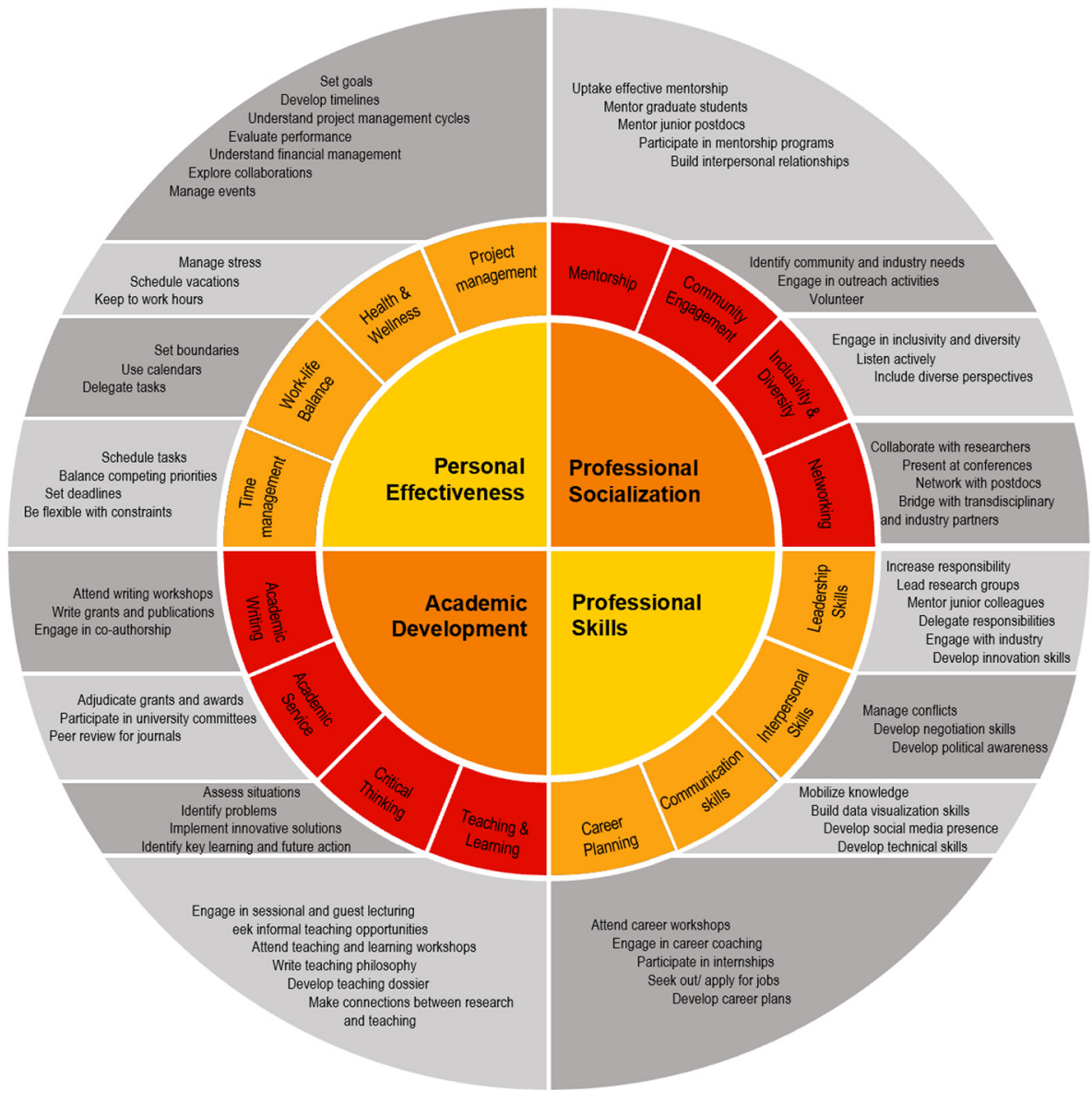

Postdoctoral scholars

357
Figure 1.

Professional learning and development (PLD) framework for postdoctoral scholars 
SGPE

12,3

358

\section{Stakeholder consultations}

We engaged in ongoing consultations with postdocs, postdoctoral supervisors, educational development consultants and associate deans of research throughout data collection, analysis and framework development. During the consultations, stakeholders were presented with the emerging themes to provide feedback on the relevance, gaps and applicability. The stakeholder feedback was integrated iteratively into the final visual framework and associated summary.

\section{Results}

A tangible result of this research is the PLD framework for postdoctoral scholars (Figure 1). The PLD framework consists of four major domains, namely, professional socialization; professional skills; academic development; and, personal effectiveness. The 4 major domains are subdivided into 16 subdomains that represent the various skills and competencies that postdoctoral scholars can build throughout their postdoctoral fellowships. Figure 1 provides

Figure 2.

Connection between the various subdomains within the professional learning and development framework for postdoctoral scholars

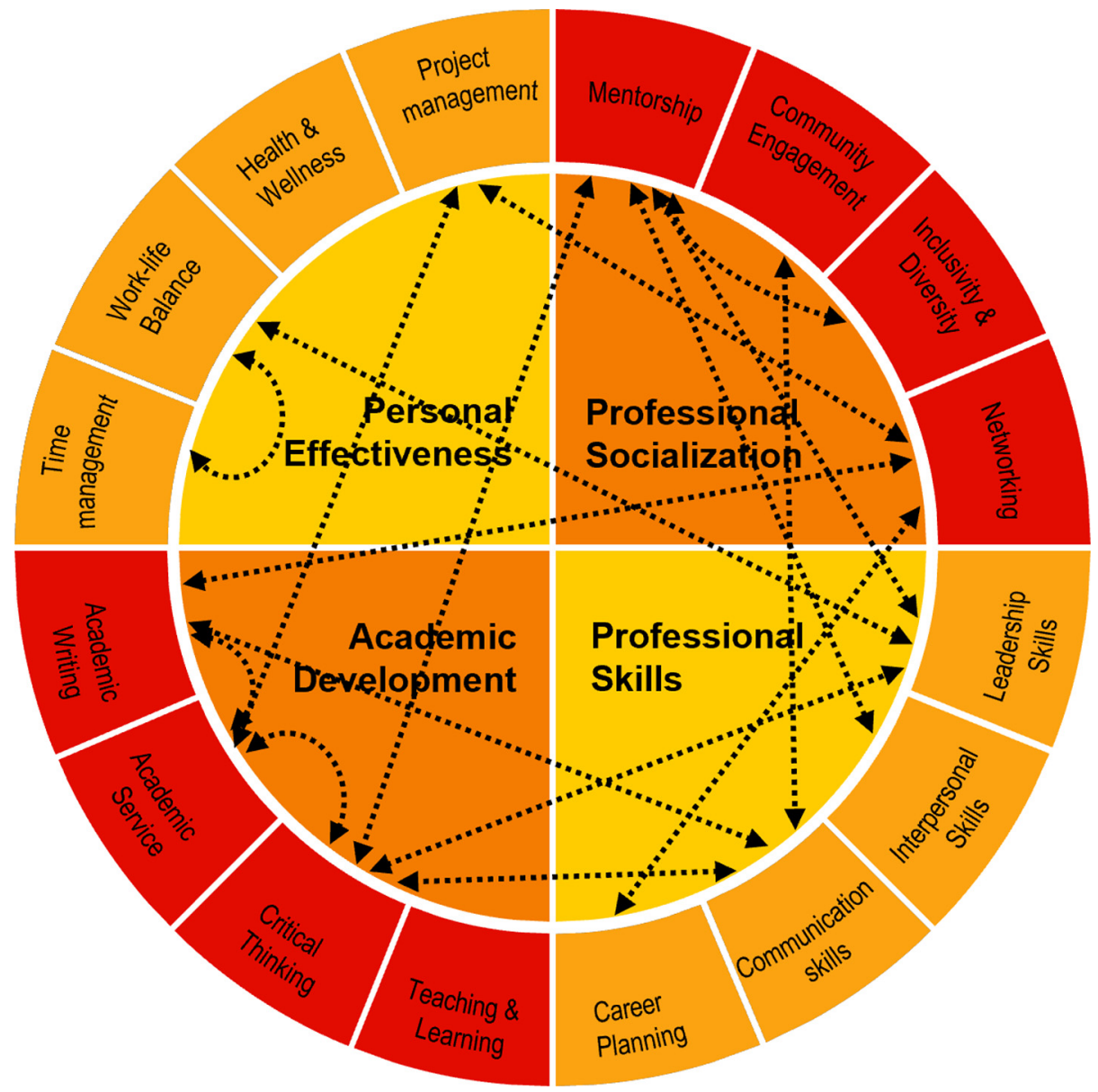


an overview of the major domains and sub-domains and represents a visual anchor for the presentation of the findings below. Figure 2 demonstrates the connection between the various subdomains within the PLD framework.

Postdoctoral scholars

\section{Professional socialization}

Professional socialization was described as the process of learning the norms, attitudes, behaviors, skills, roles and values of a profession. Postdocs and postdoc supervisors noted professional socialization as an important area for development. Participation in mentorship, community engagement and networking opportunities were recognized as ways to support professional socialization. Engaging in professional socialization activities may also help postdocs develop insight into concepts of inclusivity and diversity, which are important in any diverse collaborative environment.

Mentorship. The uptake of effective mentorship opportunities was identified as one way to improve professional socialization. Postdoc supervisors suggested developing proficiency in listening, giving and receiving feedback and responding perceptively may help with professional socialization among postdocs. Mentoring graduate students and junior postdocs to develop research and dissemination skills can support the performance of these less experienced researchers. Participation in mentorship programs can help postdocs to build interpersonal relationships (a sub-category in the professional skills domain).

Community engagement. Community engagement was identified as a key component of professional socialization. Postdocs recognized that identifying community needs by engaging with stakeholders and users of research can extend the influence and impact of research. Postdoc supervisors suggested involvement and participation in community outreach to help postdocs understand and appreciate the value of public engagement. Encouraging postdocs to engage in local opportunities and present research at public events can facilitate open interactions and cultivate professional socialization and a sense of community. Furthermore, postdocs viewed volunteering as a way to serve the communities they aim to positively impact with their research. Community engagement skills are closely linked to communication skills categorized in the professional skills domain.

Inclusivity and diversity. Another important aspect of professional socialization is to recognize opportunities for inclusivity and diversity. Postdocs expressed a desire to engage in processes of inclusivity and diversity to help build skills and demonstrate flexibility and open-mindedness as professionals. Postdocs who build skills in active listening and demonstrate an appreciation of diversity in various contexts become role models for less experienced researchers. The concept of role modeling here links to mentorship, in the same professional socialization domain. Including diverse perspectives was recognized by postdoc supervisors as one way to enrich research projects and outputs and in so doing encourage professional socialization among postdocs.

Networking. Networking is a cornerstone of professional socialization. Postdocs indicated they valued collaboration with researchers, both within their institution and in the wider research community. Collaboration links to project management categorized in the personal effectiveness domain. Presenting at conferences and building personal, professional and/or online networks with other postdocs were suggested as tools to gather feedback, advise and critical appraisal of work and for responding to opportunities. Bridging with transdisciplinary partners and recognizing connections between one's own and others' research helped postdocs identify patterns and synthesize information at a higher level. Postdocs also recognized the importance of sharing knowledge and developing networks with industry. Transdisciplinary networks also helped postdocs make imaginative leaps of understanding across research areas within and beyond academia. 
SGPE

12,3

\section{Professional skills}

Professional skills are seldom taught as part of degree programs. However, professional skills such as leadership skills, interpersonal skills, communication skills and career planning are essential for success in any career. Postdocs and postdoc supervisors recognized the need for postdocs to develop professional skills to be ready for career opportunities. They further noted a desire for postdocs to develop increased responsibility and engage with industry partners to develop the professional skills needed in today's job market.

Leadership skills. Leadership is an important professional skill for careers inside and outside of academia. Postdocs identified that they were able to develop leadership skills through taking responsibility for building and leading research groups. When postdocs developed a collaborative working environment in which they mentored junior colleagues and learned to delegate responsibilities among team members, they were able to advance their professional leadership abilities. In this way, leadership links to mentorship categorized in the professional socialization domain. Postdoc supervisors identified a need for postdocs to engage with industry and develop an appreciation of the roles that creativity and innovation play in research, to help build their leadership capacity. Furthermore, postdocs' leadership skills can be enhanced by learning to combine a range of research methods and techniques in innovative ways.

Interpersonal skills. An integral part of the suite of professional skills is interpersonal skills. Postdocs valued developing interpersonal and conflict management skills through teamwork. Postdoc supervisors recognized the need for postdocs to develop negotiation skills to help yield better collaborative results. Postdoc supervisors indicated that developing greater political awareness and abilities to handle workplace conflicts were important attributes for improving overall professional skills.

Communication skills. Understanding, interpreting and communicating effectively were identified as key professional skills for postdocs' development. Knowledge mobilization making evidence from research accessible, understandable and useful for a variety of audiences - requires postdocs to develop skills in a range of communication modes (e.g. faceto-face, interactive technologies, textual and visual media). Postdocs desired opportunities to build data visualization skills, use interactive technologies and cultivate a research presence on social media to expand their communication skills. Concurrently, postdoc supervisors encouraged postdocs to develop an awareness of the importance and risks associated with a social media presence. Postdocs were encouraged to develop technical skills, use a range of technology tools and techniques and stay current with the latest relevant communication technologies to promote digital academic conversations and networking, while reaching wider audiences with their research.

Career planning. Career planning activities constitute valuable additions to a postdoc's professional skills. Career workshops, career coaching and internships help postdocs to effectively plan their career pathway and apply for jobs. Career coaching helps postdocs identify their development needs and can also help them demonstrate initiative to build competencies in a broader context. Career coaching further helps postdocs develop career plans by setting realistic, achievable goals and developing ways to improve their employability. Postdocs recognized internships and work placements as valuable ways to build and sustain networks and relationships in academia and beyond. This links to networking categorized in the professional socialization domain. Applying for jobs allows postdocs to present their skills, personal attributes and experiences through effective curriculum vitae (CVs), applications and interviews. 
Academic development focuses on activities to enhance dimensions of teaching, learning and scholarship, commonly associated with academia and identified as another important aspect of professional learning for postdocs. Postdocs viewed opportunities to improve their critical thinking, enhance their academic writing and engage in academic service through university committee work as important in fostering their academic development. Exposure to a variety of teaching and learning experiences was also identified as impactful in postdocs' academic development.

Teaching and learning. Educational development consultants and postdocs suggested that engaging in formal teaching and learning opportunities, for example, sessional teaching and guest lecturing, serves to foster postdocs' academic development by increasing their awareness of their own approaches and teaching techniques. Postdocs viewed informal teaching of junior colleagues as one way to build teaching and learning skills, in the absence of formal teaching opportunities. Attending teaching and learning workshops, writing a teaching philosophy and developing a teaching dossier are activities that offer postdocs opportunities to formulate a wider repertoire of teaching and learning skills and practices. This contributes to making stronger connections between research and teaching.

Critical thinking. Postdocs and postdoc supervisors identified critical thinking skills as an important area for academic development. Postdocs can develop these skills by assessing situations and analyzing their own and others' work, using a range of methods. Cultivating critical judgment can lead to improved problem identification and can encourage the implementation of innovative solutions using creative methods. Innovating solutions closely links to leadership skills in the professional skills domain. Building entrepreneurial skills can help postdocs turn ideas into ventures, which enriches research and the transfer of knowledge and expertise to wider audiences. Such knowledge mobilization is an important communication skill (as noted in the professional skills domain). Making sound and realistic evidence-based judgments also stimulates critical and analytical thinking in less experienced researchers and peers, which also provides opportunities for mentorship, a component of the professional socialization domain.

Academic service. Postdocs and postdoc supervisors suggested involvement in university committees and grant and award adjudication processes as effective ways to develop insight into academic roles and responsibilities, thus promoting postdocs' academic development. Participation in peer reviewing for journals and reviewing of funding applications were recognized as ways to develop academic efficiency, as these forms of academic service enable a postdoc to engage in critical thinking and research writing, often beyond their own academic institutions.

Academic writing. Postdocs and postdoc supervisors identified academic writing as a key part of academic development that has value across career trajectories, where a variety of written outputs may be required. Postdocs expressed a desire to develop their academic writing through writing grants and publications and by participating in writing workshops. Working on grants and publications with others alerted postdocs to opportunities for broader dissemination. In this way, academic writing links to communication skills, categorized in the professional skills domain and to networking, categorized in the professional socialization domain. Co-authorship further helped postdocs to understand attribution and its fair application while recognizing the contributions of others.

\section{Personal effectiveness}

Personal effectiveness is the ability to use time and resources efficiently to perform required work. Postdocs and postdoc supervisors identified personal effectiveness as a focus area for 
SGPE

12,3

362

overall professional development. Personal effectiveness skills such as time management, nurturing work-life balance, maintaining health and wellness and project management were highlighted by several study participants.

Time management. Time management is an important skill to enhance the personal effectiveness of postdocs. Postdocs perceived the need to establish time management systems to effectively complete their research projects on time. Postdocs and postdoc supervisors highlighted the need to learn about project management cycles, scheduling and prioritizing tasks, setting deadlines and responding flexibly to constraints.

Work-life balance. Maintaining a balance between work and personal life influences personal effectiveness. Work-life balance is seldom foregrounded in academic settings and postdocs suggested that promoting effective work-life balance in their teams could raise awareness about work-life balance issues common in academic settings. Postdocs suggested that noticing the pressure on colleagues and helping less experienced researchers to balance work responsibilities with competing demands stimulated personal and team effectiveness. Postdocs wanted to learn to set boundaries, yet this was not something commonly modeled by their supervisors. Using calendars to plan and delegate tasks is a skill that enables the effective utilization of resources so that the well-being of postdocs and the teams they lead can ultimately be enhanced. Work-life balance is closely linked to time management (in the personal effectiveness domain) and leadership skills (in the professional skills domain).

Health and wellness. Health and wellness are associated with work efficiency, the ability for complex decision-making, creativity, concentration and resistance to stress, which all contribute to personal effectiveness. Postdocs and their supervisors recognized the need for postdocs to develop sensitivity to signs of stress in self, colleagues, students and staff. Postdocs identified a need to develop coping strategies and confidence in seeking and providing support, where necessary. Clearly, communicating vacation schedules and work hours and keeping to what was agreed upon were suggested for promoting the health and well-being of postdocs and their teams.

Project management. Successful projects often depend on managing strategies, goals and actions, which are closely related to personal effectiveness. Setting goals, developing timelines and prioritizing activities were recognized as strategies that could enhance project management skills among postdocs. Postdocs expressed a need to understand project management cycles and draw on project management tools and techniques to be more efficient project managers. Evaluating performance and critically reflecting on project management experiences may help postdocs to identify areas of strengths and opportunities for growth. Additionally, postdocs and their supervisors identified a common need to develop a clear understanding of the principles of financial management to improve project management. Exploring collaborations with colleagues within their own and adjacent disciplines, and with stakeholders and users of research to co-produce research outputs, may be meaningful strategies for practicing multi- or cross-disciplinary project management skills. This is closely linked to networking skills (in the professional skills domain) and to academic writing (in the academic development domain). Training in managing events, such as conferences and research meetings, may also improve the managerial skills of postdocs. Stakeholder consultations affirmed the importance of postdocs gaining skills in managing finances and events.

\section{Discussion}

The findings from this multiphase research resulted in an evidence informed PLD framework for postdoctoral scholars (Figure 1). The PLD framework highlights professional socialization, professional skills, academic development and personal effectiveness, which 
include fundamental skills that may impact postdocs' overall PLD during their postdoc tenure and beyond. The components of the framework are based on previous research, surveys and interviews, as well as consultations with stakeholders. The major domains of the framework are interconnected through links between its subcategories (Figure 2). We suggest that optimal development of postdocs will be achieved through an integration of the different skills development areas while acknowledging some skills are transferrable to other areas of development.

In our PLD framework, one quarter of the professional development skills focus on the academic career trajectory while the remaining three quarters are dedicated to skills that are highly transferable and translatable in other career paths. With fewer than $20 \%$ of postdocs entering permanent academic positions (Edge and Munro, 2015; Fuhrmann et al., 2011) it is imperative that postdocs and postdoc supervisors become aware of the need to develop skills that support success in both academic and non-academic settings. The PLD framework provides clear direction for universities to further support the career development of postdocs, as job markets and workforce needs shift and expand (Ålund $e$ t al., 2020). We contend that this framework can be used to bring the relative ratio of required skills to the attention of postdocs and institutions wishing to develop robust postdoc support.

We acknowledge there are numerous researcher development frameworks including the rigorously developed Vitae Researcher Development Framework (Vitae Careers Research and Advisory Centre, 2021). We argue our PLD framework adds to this work by acknowledging the unique needs and experiences of postdocs who often find themselves in precarious positions with limited numbers of academic and research positions available to them post-fellowship. The PLD framework was strategically developed in consultation with multiple stakeholders who provided information and insight on the specific PLD needs of postdocs.

While the need to expand PLD has been acknowledged previously (Brownell and Tanner, 2012; Nerad and Cerny, 1999; Rybarczyk et al., 2011; Silva et al., 2016), our PDL framework highlights the diverse skills needed to support postdocs as they negotiate the complexities of their future careers. Many postdoc professional learning opportunities emphasize peerreviewed publications and securing research funding. Our framework contributes to scholarly knowledge by expanding and accentuating additional skills postdocs need to acquire related to personal effectiveness, professional socialization, professional skills and academic development. It also draws attention to emerging academic conversations related to employability, teaching expertise, academic socialization, networking across disciplines, community and industry engagement, equity, diversity and inclusion, as well as academic health and well-being.

\section{Professional socialization}

The PLD framework recognizes mentorship as one way to support the professional socialization of postdocs. The importance of mentorship has also been suggested by AbuYousif et al. (2010), Gerdeman et al. (2007) and Holtzclaw et al. (2005) in their studies to determine the scope of postdoc PLD. Kuhn and Castano (2016) found participants of a mentorship program were more successful in job interviews and more confident in exploring non-traditional careers when compared to non-participants. In the PLD framework, mentorship skills relate to networking, inclusivity and diversity, critical thinking and interpersonal skills.

Community engagement is the second category of professional socialization. Along with community-engaged research, community engagement is increasingly viewed as key to
Postdoctoral scholars

363 
SGPE

12,3

translating research into practice (Michener et al., 2012). Through this kind of knowledge mobilization, it is clear how community engagement is related to communication skills, a central theme of the professional skills domain in the PLD framework.

Opportunities for postdocs to develop skills that support diversity and inclusivity can enrich research projects and promote professional socialization. Indeed, learning inclusive behaviors that enable members from minority and marginalized communities to feel respected and engaged is important across career trajectories (Buse et al., 2016). In the PLD framework, inclusivity and diversity are related to mentorship in the same domain (professional socialization).

Our finding that postdocs valued networking with other researchers align with the results of other studies. Through interviews with postdocs, Åkerlind (2005) identified a common need for the development of supportive networks, as postdocs often work in isolation. Chen et al. (2015) found that postdocs who developed a peer network during their appointment had smoother transitions and more positive experiences in preparing for their careers. Similarly, Baiduc et al. (2016) observed that for postdocs in a professional development program one of the most useful benefits was peer interaction. In our PLD framework, networking relates to career planning, project management and academic writing.

\section{Professional skills}

Leadership is an imperative professional skill for success in many careers (Smith et al., 2002). Leadership skills development workshops have been implemented in several postdoc professional development programs (Aschwanden, 2007; Bessent, 1989; Richmond, 2005) and were found to benefit the career paths of female postdocs specifically. Through accepting greater responsibility and mentoring junior colleagues, postdocs can advance their leadership skills. In our PLD framework, leadership skills related to mentorship, worklife balance and critical thinking.

Postdoctoral training is an excellent time to expand interpersonal behaviors and skills essential for success in numerous careers (Smith et al., 2002). As scientists, postdocs are often focused on optimizing efficiency and performance in research but may be unaware of the impact that social dynamics and interpersonal skills can have on collaboration (Cohen and Cohen, 2005). Interpersonal skills relate to mentorship in our PLD framework.

Communication and knowledge mobilization skills have been identified as important professional skills for postdocs to develop (Bessudnov et al., 2015; Kuhn and Castano, 2016). The ability to explain science to non-scientists was highlighted as an important professional skill in the evaluation of an integrated training program for postdocs (Phillips, 2010). Communication skills related to community engagement, academic writing and critical thinking in our PLD framework.

Our framework suggests that career planning is a beneficial PLD opportunity for postdocs. Matyas et al. (2011) likewise revealed postdocs' desire to learn about career options, job searching and interviewing. The benefits of participation in such initiatives were highlighted by Gerdeman et al. (2007) for exposing postdocs to job options and improving job searching. Career planning relates to networking in our PLD framework.

\section{Academic development}

Our results showed that teaching and learning opportunities encouraged postdocs to reflect upon their teaching abilities and techniques and formulate individual growth plans for further development. In a recent study on a postdoc teaching and learning certificate, over 
$91 \%$ of participants indicated they feel more prepared as instructors and will be able to apply their learnings in the future (Nowell et al., 2020).

Critical thinking is a crucial twenty-first century skill for all professionals (Shavelson et al., 2019). It strengthens postdocs' academic abilities and prepares them as professionals for various work environments (Mahanal et al., 2019). Critical thinking involves not only the acquisition of information but also active learning, problem-solving, joint decision-making and information utilization. It can also enhance postdocs' ability to transfer knowledge between disciplines. Critical thinking relates to academic service, mentorship, leadership skills and communication skills in our PLD framework.

Historically, postdocs have focused on developing individual programs of research and may have neglected teaching and service requirements commonly associated with tenure track positions (Jones and Oakley, 2018). Academic service, including adjudication, committees and peer review, can provide postdocs with learning opportunities in areas such as teamwork and critical thinking (Cress et al., 2001; Kuh, 1994; Kuh and Lund, 1994). Our PLD framework acknowledges that academic service provides an essential opportunity for postdocs to experience and contribute to academic governance, communities and processes and shows how academic service relates to critical thinking, project management and academic writing.

Development of academic writing and grantsmanship, through co-authoring academic publications and writing grant proposals, was suggested to improve postdocs' academic development (Chang, 2008). Postdocs have previously identified the need for opportunities to develop skills in academic writing (Åkerlind, 2005; Jadavji et al., 2016; Matyas et al., 2011) and presentation (Mitchell et al., 2013). Postdocs who engaged in writing workshops reported improved writing and peer-reviewing skills, and enhanced writing productivity (Gianaros, 2006). In our PLD framework, academic writing relates to networking, communication skills and academic service.

\section{Personal effectiveness}

Time management behaviors are related to academic performance and personal effectiveness (Claessens, 2004; Noftle and Robbins, 2007). In our PLD framework, time management also relates to work-life balance as an important contributor to personal effectiveness. Kuhn and Castano (2016) also found an improved work-life balance to be a key outcome of postdoc peer-mentorship programs that contributed to increased personal effectiveness. Several other studies have illustrated the development of strategies for maintaining work-life balance (Bessudnov et al., 2015; Kuhn and Castano, 2016; Matyas et al., 2011). While research suggests that postdocs aspire to develop better time management and work-life balance (Burke et al., 2019), our PLD framework makes explicit the need to develop these abilities as a foundational professional skill. Besides time management, work-life balance relates to leadership skills in our PLD framework.

Health and wellness support at universities may be inadequate when compared to other types of organizations (Jacobs and Winslow, 2004; Winefield et al., 2008). Work-life conflict and job demands are associated with stress-related work and health outcomes, and burnout, especially for new academics (Sabagh et al., 2018). Such burnout can be offset through individual coping and work management strategies (Sabagh et al., 2018) such as reducing job demands, role clarity, social support and closely monitoring workload and working hours. The PDL framework contributes to a growing scholarly discourse on the importance of health and well-being in academic contexts, by elevating health and wellness and worklife balance as essential professional development topics for postdocs. It aligns directly with calls to implement research-informed strategies to sustain wellness and work-life integration for our postdoctoral communities (Ålund et al., 2020). 
Our PLD framework further suggests that advanced project management skills can improve personal effectiveness. The importance of developing project management skills has also been highlighted in the Canadian Postdoc Survey by Mitchell et al. (2013). In our PLD framework, project management relates to networking and academic service.

\section{Practice implications}

As job markets and workforce needs continue to shift (Ålund et al., 2020; Council of Canadian Academies, 2021), the PDL framework provides a tool for universities to systematically and intentionally address the changing PLD needs of postdoctoral scholars. Systemic organizational learning and change require intentionality across multiple levels. For example, Hannah and Lester (2009) suggest that sustained organizational learning is supported by:

- strengthening the capacity and expertise of individuals at the micro-level;

- developing integrated networks and strengthening local leadership at the unit, department, faculty, working group or meso-level; and

- and providing the vision, policies, processes, resources and structures for change at the institutional or macro-level.

Our results will be useful to several target audiences across multiple organizational levels, including postdocs, postdoc supervisors, faculties, departments, interdisciplinary working groups, institutional decision-makers and researchers. For example, postdocs and their supervisors could use this framework to engage in mentorship conversations, to establish professional learning plans and to foster critical reflection and career growth (individual or micro-level). Institutional research offices, faculties, departments, cross-disciplinary working groups and teaching and learning centers could use this framework to guide program development targeted to postdocs' needs (meso and macro-level). Institutional, regional, national and international postdoctoral associations could use this framework to amplify conversations and develop strategies to foster professional learning, growth, success and impact of postdoctoral researchers (macro-level) and to help foster broader cultural change in how postdoctoral positions are conceptualized, developed and supported in the academy. The PLD framework may also have relevance in graduate education as recognition of the need to prepare students for diverse careers grows.

Postdoctoral administrators typically have limited resources for postdoc professional development. The PLD framework will help administrators plan properly balanced professional development offerings that address the diversity of needs in the postdoc community. The framework can also help administrators to identify potential synergies, where offerings on one topic can benefit postdoc development on related topics. Importantly, the PLD framework can help ensure that professional development programming balances the needs of postdocs to prepare them for a diversity of careers within and beyond academia.

\section{Strengths and limitations}

This research reflects the global state of evidence for PLD for postdoctoral scholars, and the current state of such learning and development at one Canadian university. Including participants from a range of disciplines strengthened this study. Participant diversity allowed for exploration of the complexity and variation of PLD to increase our understanding of this concept. Triangulating all phases of this study into an evidence-informed framework strengthens the findings, while underscoring the need for additional research with robust study designs to better understand PLD processes, impact and outcomes for postdocs. 
While a systematic, rigorous approach was followed, this study is not without limitations and caveats. Despite a comprehensive and systematic literature search, some relevant literature might have been missed. PLD for postdocs varied across the literature, making comparison challenging, yet simultaneously revealing knowledge about the range of approaches taken and the benefits and challenges associated with each. Although the literature informing this work is globally representative, the documents, survey and interview data, as well as the stakeholder consultations, were gathered from one research intensive university in Canada and may not accurately reflect the PLD of postdocs at other institutions.

\section{Future research}

Existing PLD opportunities for postdocs may not be robust, but the global need for postdocs to develop skills for various career trajectories is clear (Nowell et al., 2018; Nowell et al., 2019). Rigorous evaluation of the impact of and investment in PLD for postdocs is needed. The available literature shows that few such offerings are evaluated.

Ongoing formative and summative evaluation, using defined benchmarks, is required. To begin to measure the impact of PLD for postdocs, qualitative (e.g. questionnaires, interviews and review of $\mathrm{CVs}$ ) and quantitative (e.g. number of postdocs engaged in such offerings) data could be collected across institutions and countries. Short-term outcome measures could include satisfaction with skill development, productivity and work-life balance. Longer-term outcome measures could include tracking of employment, retention and skill development over time. Further research should also focus on the strengths and limitations of the various PLD opportunities to inform decision-makers when they design such opportunities for postdocs.

There are few comparative research designs and no experimental, quasi-experimental, longitudinal or multi-site research about PLD of postdocs. Causal connections between PLD and career outcomes require comparison group designs that allow for the examination of covariates. Similarly, future longitudinal research could explore the impact of PLD over time. All studies would benefit from the increased power derived from multi-site design and evaluation. Based on the expressed need for postdocs to engage in PLD, careful development, implementation and evaluation of PLD opportunities is recommended to rigorously assess the impact for postdocs.

\section{Conclusions}

This evidence-based PLD framework has been developed by and for postdocs as an aid for planning, promoting and enhancing PLD. It can be used to inform institution-level efforts to refine existing strategies or develop new approaches to promote postdoc professional development and to inform benchmarks for its evaluation. The PLD framework advances theoretical understanding of postdoctoral professional development and facilitates the transferability of findings to other institutions where postdocs engage in training to develop the skills required for their future careers.

\section{References}

Abu-Yousif, A., Erik, C., Skoczenski, A. and Hasan, T. (2010), "The ABC's of industry: a postdoc program provides a sneak peek into industry careers", Nature Biotechnology, Vol. 28 No. 6, pp. 625-626.

Åkerlind, G.S. (2005), "Postdoctoral researchers: roles, functions and career prospects”, Higher Education Research and Development, Vol. 24 No. 1, pp. 21-40, doi: 10.1080/0729436052000318550.

Ålund, M., Emery, N., Jarrett, B.J., MacLeod, K.J., McCreery, H.F., Mamoozadeh, N., Phillips, J.G., Schossau, J., Thompson, A.W., Warwick, A.R., Yule, K.M., Zylstra, E.R. and Gering, E. (2020), "Academic ecosystems must evolve to support a sustainable postdoc workforce", Nature Ecology and Evolution, Vol. 4 No. 6, pp. 777-781. 
SGPE

12,3

Aschwanden, C. (2007), "Transferable skills and portable careers", Science, Vol. 316 No. 5823, pp. 471-475.

Baiduc, R., Linsenmeier, R. and Ruggeri, N. (2016), "Mentored discussions of teaching: an introductory teaching development program for future STEM faculty", Innovative Higher Education, Vol. 41 No. 3, pp. 237-254.

Bessent, H. (1989), "Postdoctoral leadership training for women of color", Journal of Professional Nursing, Vol. 5 No. 5, pp. 279-282.

Bessudnov, A., Guardiancich, I. and Marimon, R. (2015), "A statistical evaluation of the effects of a structured postdoctoral programme”, Studies in Higher Education, Vol. 40 No. 9, pp. 1588-1604.

Bray, R. and Boon, S. (2011), "Towards a framework for research career development", International Journal for Researcher Development, Vol. 2 No. 2, pp. 99-116.

Brownell, S.E., Tanner, K.D. (2012), "Barriers to faculty pedagogical change: lack of training, time, incentives, and ... tensions with professional identity?", CBE - Life Sciences Education, Vol. 11 No. 4, pp. 339-346.

Burke, L.E., Hall, J., De Paiva, W.A., Alberga, A., Mu, G.M., Leigh, J.P. and Vazquez, M.S. (2019), "Postdoctoral scholars in a faculty of education: navigating liminal spaces and marginal identities", Arts and Humanities in Higher Education, Vol. 18 No. 4, pp. 329-348.

Buse, K., Bernstein, R.S. and Bilimoria, D. (2016), "The influence of board diversity, board diversity policies and practices, and board inclusion behaviors on nonprofit governance practices", Journal of Business Ethics, Vol. 133 No. 1, pp. 179-191.

Chang, S.H., Daniel, C. and Chamberlain, R. (2008), "Works-in-progress: guiding junior scientists through career development applications", Journal of Cancer Education, Vol. 23 No. 3, pp. 142-148.

Chen, S., McAlpine, L. and Amundsen, C. (2015), "Postdoctoral positions as preparation for desired careers: a narrative approach to understanding postdoctoral experience", Higher Education Research and Development, Vol. 34 No. 6, pp. 1083-1096.

Claessens, B. (2004), Perceived Control of Time: Time Management and Personal Effectiveness at Work, Technische Universiteit Eindhoven, Eindhoven.

Cohen, C.M. and Cohen, S.L. (2005), Lab Dynamics: Management Skills for Scientists, Cold Spring Harbor Laboratory Press, Cold Spring Harbor, New York, NY.

Council of Canadian Academies (2021), "Degrees of success, Ottawa (ON). The expert panel on the labour market transition of $\mathrm{PhD}$ graduates", Council of Canadian Academies, available at: www. cca-reports.ca/reports/the-labour-market-transition-of-phd-graduates/

Cress, C.M., Astin, H.S., Zimmerman, B., Oster, K. and Burkhardt, J.C. (2001), "Developmental outcomes of college students' involvement in leadership activities", Journal of College Student Development, Vol. 1, pp. 15-29.

Edge, J. and Munro, D. (2015), "Inside and outside the academy: valuing and preparing $\mathrm{PhDs}$ for careers, the conference board of Canada", available at: www.conferenceboard.ca/e-library/ abstract.aspx?did $=7564$

European Commission Directorate General for Research and Innovation (2011), "Towards a European framework for research careers", available at: https:/cdn5.euraxess.org/sites/default/files/ policy_library/towards_a_european_framework_for_research_careers_final.pdf

Evans, L. (2012), "Leadership for researcher development: what research leaders need to know and understand", Educational Management Administration and Leadership, Vol. 40 No. 4, pp. 423-435.

Evans, L. (2014), "What is effective research leadership? A research-informed perspective", Higher Education Research and Development, Vol. 33 No. 1, pp. 46-58.

Fuhrmann, C.N., Halme, D.G., O'sullivan, P.S. and Lindstaedt, B. (2011), "Improving graduate education to support a branching career pipeline: recommendations based on a survey of doctoral students in the basic biomedical sciences", CBE-Life Sciences Education, Vol. 10 No. 3, pp. 239-249. 
Gerdeman, R.D., Russell, A.A. and Eikey, R.A. (2007), “A course to prepare future faculty in chemistry: perspectives from former participants", Journal of Chemical Education, Vol. 84 No. 2, p. 285.

Gianaros, P.J. (2006), "A seminar on scientific writing for students, postdoctoral trainees, and junior faculty", Teaching of Psychology, Vol. 33, pp. 120-123.

Graham, I.D., Logan, J., Harrison, M.B., Straus, S.E., Tetroe, J., Caswell, W. and Robinson, N. (2006), "Lost in knowledge translation: time for a map?", Journal of Continuing Education in the Health Professions, Vol. 26 No. 1, pp. 13-24.

Hannah, S.T. and Lester, P.B. (2009), "A multilevel approach to building and leading learning organizations", The Leadership Quarterly, Vol. 20 No. 1, pp. 34-48.

Holtzclaw, J.D., Lee, G., Pyatt, R., Giver, C.S., Hoey, J., Haynes, J.K., Gunn, R.B., Eaton, D. and Eisen, A. (2005), "FIRST: a model for developing new science faculty", Journal of College Science Teaching, Vol. 34, pp. 24-29.

Jacobs, J.A. and Winslow, W.E. (2004), "Overworked faculty: job stresses and family demands", The Annals of the American Academy of Political and Social Science, Vol. 596 No. 1, pp. 104-129.

Jadavji, N., Adi, M., Corkery, T., Inooue, J. and Van Benthem, K. (2016), "The 2016 Canadian national postdoctoral survey report", available at: www.caps-acsp.ca/wp-content/uploads/2016/11/ 2016_CAPS-ACSP-National_Postdoc_Survey_Report.pdf

Jones, S. and Oakley, C. (2018), "The precarious postdoc: interdisciplinary research and casualised labour in the humanities and social sciences", available at: www.workingknowledgeps.com/ wpcontent/uploads/2018/04/WKPS_PrecariousPostdoc_PDF_Interactive.pdf

Kuh, G.D. (1994), Student Learning outside the Classroom: Transcending Artificial Boundaries, Office of Educational Research and Improvement, Washington, DC.

Kuh, G.D. and Lund, J.P. (1994), "What students gain from participating in student government”, New Directions for Student Services, Vol. 66, pp. 5-17.

Kuhn, C. and Castano, Z. (2016), "Boosting the career development of postdocs with a peer-to-peer mentor circles program", Nature Biotechnology, Vol. 34 No. 7, pp. 781-783.

Mahanal, S., Zubaidah, S., Sumiati, I.D., Sari, T.M. and Ismirawati, N. (2019), "Ricosre: a learning model to develop critical thinking skills for students with different academic abilities", International Journal of Instruction, Vol. 12 No. 2, pp. 417-434.

Matyas, M., Lowy, M., Sweazea, K. and Alvarez, D. (2011), "Monitoring physiology trainee needs to focus professional society responses: the APS trainee needs surveys", Advances in Physiology Education, Vol. 35 No. 2, pp. 168-177.

Michener, L., Cook, J., Ahmed, S.M., Yonas, M.A., Coyne-Beasley, T. and Aguilar-Gaxiola, S. (2012), "Aligning the goals of community-engaged research: why and how academic health centers can successfully engage with communities to improve health", Academic Medicine, Vol. 87 No. 3, pp. 285-291.

Mitchell, J., Walker, V., Annan, R., Corkery, T., Goel, N., Harvey, L., Kent, D.G., Peters, J. and Vilches, S. (2013), The 2013 Canadian Postdoc Survey: Painting a Picture of Canadian Postdoctoral Scholars, Canadian Association of Postdoctoral Scholars and Mitacs, pp. 5-39.

National Postdoctoral Association (2021), "Providing a national voice and seeking positive change for postdoctoral scholars", available at: www.nationalpostdoc.org/

Nerad, M. and Cerny, J. (1999), "Postdoctoral patterns, career advancement, and problems", Science, Vol. 285 No. 5433, pp. 1533-1535.

Noftle, E.E. and Robins, R.W. (2007), "Personality predictors of academic outcomes: big five correlates of GPA and SAT scores", Personality Processes and Individual Differences, Vol. 93, pp. 116-130.

Nowell, L., Ovie, G., Berenson, C., Kenny, N. and Hayden, K.A. (2018), "Professional learning and development of postdoctoral scholars: a systematic review of the literature", Education Research International, Vol. 2018, p. 5950739.

Postdoctoral scholars 
SGPE

12,3

Nowell, L., Ovie, G., Kenny, N., Hayden, K.A. and Jacobsen, M. (2019), "Professional learning and development initiatives for postdoctoral scholars", Studies in Graduate and Postdoctoral Education, Vol. 11 No. 1, pp. 35-55.

Nowell, L., Ovie, G., Kenny, N. and Jacobsen, M. (2020), "Postdoctoral scholar's perspectives about professional learning and development: a concurrent mixed-methods study", Palgrave Communications, Vol. 6 No. 1.

O'Cathain, A., Murphy, E. and Nicholl, J. (2010), "Three techniques for integrating data in mixed methods studies", BMJ, Vol. 341 No. sep17 1, pp. 1147-1150.

Phillips, R.A. (2010), "Encouraging a more enterprising researcher: the implementation of an integrated training programme of enterprise for Ph.D. and postdoctoral researchers", Research in PostCompulsory Education, Vol. 15 No. 3, pp. 289-299.

Powell, K. (2015), "The future of the postdoc”, Nature, Vol. 520 No. 7546, p. 144+.

Richmond, G.L. (2005), "COAChing women to succeed in academic careers in the chemical sciences", Journal of Chemical Education, Vol. 82 No. 3, pp. 351-353.

Rybarczyk, B., Lerea, L., Lund, P.K., Whittington, D. and Dykstra, L. (2011), "Postdoctoral training aligned with the academic professoriate", BioScience, Vol. 61 No. 9, pp. 699-705.

Sabagh, Z., Hall, N.C. and Saroyan, A. (2018), "Antecedents, correlates and consequences of faculty burnout”, Educational Research, Vol. 60 No. 2, pp. 131-156.

Sauermann, H. and Roach, M. (2016), "Why pursue the postdoc path?”, Science, Vol. 352 No. 6286, pp. 663-664.

Shavelson, R., Zlatkin-Troitschanskaia, O., Beck, K., Schmidt, S. and Marino, J. (2019), “Assessment of university students' critical thinking: next generation performance assessment”, International Journal of Testing, Vol. 19 No. 4, pp. 337-362.

Silva, E.A., Des Jarlais, C., Lindstaedt, B., Rotman, E. and Watkins, E.S. (2016), "Tracking career outcomes for postdoctoral scholars: a call to action", PLOS Biology, Vol. 14 No. 5, p. e1002458.

Smith, S., Pedersen-Gallegos, L. and Riegle-Crumb, C. (2002), "The training, careers, and work of Ph.D. physical scientists: not simply academic", American Journal of Physics, Vol. 70 No. 11, pp. 1081-1092.

University of Cambridge (2021), "Cambridge researcher development framework”, available at: www. rdp.cam.ac.uk/camrdf

Vitae Careers Research and Advisory Centre (2021), "About the vitae researcher development framework", available at: www.vitae.ac.uk/researchers-professional-development/about-thevitae-researcher-development-framework

Wendler, M.C. (2001), "Triangulation using a meta-matrix1", Journal of Advanced Nursing, Vol. 35 No. 4, pp. 521-525.

Winefield, A.H., Boyd, C., Saebel, J. and Pignata, S. (2008), Job Stress in University Staff: An Australian Research Study, Australian Academic Press, Bowen Hills, Queensland.

\section{Corresponding author}

Lorelli Nowell can be contacted at: lnowell@ucalgary.ca

For instructions on how to order reprints of this article, please visit our website: 